\title{
Efeito da incorporação de chamote no processamento e microestrutura de cerâmica vermelha
}

\section{(Effect of grog incorporation in the processing and microstructure of red ceramic)}

\author{
C. M. F. Vieira, E. T. A. de Souza, S. N. Monteiro \\ Laboratório de Materiais Avançados (LAMAV) \\ Universidade Estadual do Norte Fluminense - UENF \\ Av. Alberto Lamego 2000, Horto, Campos dos Goytacazes, RJ \\ vieira@uenf.br
}

\begin{abstract}
Resumo
Este trabalho tem por objetivo avaliar o efeito da incorporação de chamote, obtido de rejeitos de tijolos queimados em baixas temperaturas, em massa de cerâmica vermelha visando à obtenção de telhas. Inicialmente o chamote foi submetido a ensaios de caracterização química, física e mineralógica. Em seguida, foram feitas adições de chamote a uma argila caulinítica nas proporções de $0,5,10$, e $20 \%$ em peso. Foram preparados corpos-de-prova por extrusão para queima em forno industrial a $970{ }^{\circ} \mathrm{C}$. As propriedades tecnológicas avaliadas foram: absorção de água, retração linear e tensão de ruptura à flexão. A microestrutura das composições foi avaliada através de ensaios de porosimetria de mercúrio e microscopia eletrônica de varredura. Os resultados indicaram que a incorporação de chamote melhorou os parâmetros de secagem da cerâmica. Após queima, a porosidade praticamente não sofreu variações significativas com a incorporação de chamote. Isto indica que a queima de chamote em temperaturas superiores àquela em que ele foi obtido, propicia sua própria sinterização e não ocasiona alterações degenerativas na microestrutura das cerâmicas queimadas. Palavras-chave: cerâmica vermelha, chamote, microestrutura, processamento, propriedades.
\end{abstract}

\section{Abstract}

This work has for objective to evaluate the incorporation of grog, obtained from wastes of bricks fired at low temperatures, in a red ceramic body aiming at the production of roofing tiles. Initially the grog was chemical, physical and mineralogical characterized. Extruded samples were prepared for firing in an industrial furnace at $970{ }^{\circ} \mathrm{C}$. The technological properties evaluated were: linear shrinkage, water absorption and flexural rupture strength. The microstructure of fired samples was evaluated by pore-size distribution and scanning electron microscopy. The results showed that grog addition enhanced the drying parameters of the ceramic. After firing, the porosity practically did not changed with grog addition. This indicates that the firing of grog at temperatures above the one it was obtained makes possible its own sintering and does not introduce negative changes in the microstructure of the fired ceramics.

Keywords: red ceramic, grog, microstructure, processing, properties.

\section{INTRODUÇÃO}

Chamote de descarte de produtos cerâmicos após queima é um dos materiais não plásticos eventualmente incorporados em massas para a produção de cerâmicas. $\mathrm{Na}$ obtenção do chamote há inicialmente necessidade de fragmentação das peças descartadas, o que ocorre geralmente em moinhos de martelos. A utilização de chamote em cerâmica vermelha pode ter reflexos positivos sobre todo o processo produtivo. $\mathrm{O}$ chamote por apresentar uma granulometria mais grosseira do que a argila pode melhorar o grau de empacotamento. Além disso, devido à morfologia das partículas, contribui significativamente para facilitar a etapa de secagem. Entretanto, o teor de adição e a granulometria são fatores determinantes para a otimização do processo [1-7]. Durante a queima, até temperaturas não superiores ao seu processamento, o chamote irá se comportar como material inerte. Já a utilização de chamote em temperaturas de queima superiores à qual foi obtido, possibilitará o desenvolvimento de reações de sinterização. Neste caso, a menor perda de massa do chamote em comparação com as argilas também pode contribuir para uma redução da porosidade do produto final.

A fabricação de cerâmicas vermelhas em Campos dos Goytacazes, norte do Estado do Rio de Janeiro varia significativamente em função da época do ano, sendo também influenciada pelas leis de mercado. Já se chegou a fabricar 135 milhões de peças/mês, mas atualmente a fabricação de cerâmica vermelha situa-se em torno de 70 milhões de peças/mês. A produção está voltada sobretudo para a fabricação de blocos de vedação, que se constitui em um tipo de produto de baixo valor agregado. Há ainda uma pequena produção de telhas, pisos extrudados, plaquetas para revestimento, bloco estrutural e tijolos aparente. Mão-de-obra não qualificada, defasagem tecnológica e ausência de controle de qualidade são fatores que contribuem para a obtenção de produtos com inconstância nas suas propriedades e que, em muitos casos, não atendem às normas técnicas. 
Em Campos dos Goytacazes, os blocos de vedação ou simplesmente tijolos furados, sem finalidade estrutural, correspondem a aproximadamente $90 \%$ da produção. Estes tijolos são normalmente queimados em fornos do tipo Hoffmann em temperaturas da ordem $600{ }^{\circ} \mathrm{C}$, utilizando-se principalmente lenha como combustível. Há um percentual de perda após queima bastante variado. As cerâmicas que adotam critérios de controle de qualidade apresentam uma perda na etapa de queima entre $0,5 \%$ e $1 \%$. Entretanto, algumas cerâmicas chegam a apresentar $10 \%$ de perda da produção somente na etapa de queima. Normalmente os rejeitos de peças queimadas são depositados no próprio pátio das indústrias ou no acostamento ao longo da rodovia que margeia a maior parte das indústrias.

Em relação às telhas, quatro empresas em Campos dos Goytacazes as fabricam prensadas nos tipos romana e portuguesa. Estima-se uma produção de 800.000 peças/mês obtidas em fornos Hoffmann e Paulistinha, em temperaturas variando de $850^{\circ} \mathrm{C}$ a $970{ }^{\circ} \mathrm{C}$. Estas cerâmicas utilizam lenha e gás natural como combustíveis. As telhas, entretanto, apresentam excessiva porosidade o que acarreta valores de absorção de água fora das especificações técnicas. Os principais fatores que contribuem para isto são as características das argilas, com destaque para seu caráter predominantemente caulinítico. Isto acarreta um comportamento de queima refratário associado à elevada perda de massa durante a queima devido ao alto percentual de minerais argilosos [8-9]. Ou seja, as argilas de Campos dos Goytacazes são extremamente adequadas para fabricação de blocos de vedação mas não para fabricação de telhas. Uma alternativa para viabilizar a produção de telhas de qualidade é a reformulação das massas cerâmicas atualmente utilizadas. Isto vem sendo pesquisado através da incorporação de materiais que possibilitem uma redução tanto da refratariedade quanto da perda de massa durante a queima.

Vale lembrar que as telhas são produtos que apresentam valor agregado superior aos blocos de vedação. Estima-se que no Estado do Rio de Janeiro aproximadamente $90 \%$ das telhas cerâmicas comercializadas sejam provenientes de outros estados. Estes fatores mostram que a fabricação de telhas pode ser uma saída para a revitalização da indústria de cerâmica vermelha do município de Campos dos Goytacazes. Entretanto, as dificuldades encontradas para a obtenção de telhas de qualidade desestimulam um incremento na sua produção.

Neste sentido, este trabalho tem como objetivo avaliar a influência da incorporação de um chamote proveniente da queima de blocos de vedação em baixas temperaturas no processamento, propriedades e microestrutura de massa argilosa visando à fabricação de telhas dentro das especificações técnicas.

\section{MATERIAIS E MÉTODOS}

Para realização deste trabalho foram utilizados os seguintes materiais: argila caulinítica utilizada para fabricação de cerâmica vermelha e chamote proveniente de refugo de blocos de vedação (tijolos) queimados a aproximadamente $600{ }^{\circ} \mathrm{C}$. Ambas as matérias-primas são provenientes de indústrias cerâmicas de Campos dos Goytacazes.

Após coleta das matérias-primas, foi realizado um beneficiamento diferenciado para cada material. A argila foi inicialmente seca em estufa a $110^{\circ} \mathrm{C}$, destorroada em almofariz de porcelana e peneirada em malha 20 (abertura $840 \mu \mathrm{m}$ ). Já o chamote foi obtido por trituração manual de descarte de blocos de vedação e posterior peneiramento em malha 40 (abertura $425 \mu \mathrm{m}$ ).

O chamote foi submetido a ensaios de composição química, difração de raios $X$ (DRX) e distribuição de tamanho de partícula. A composição química da argila do chamote foi determinada por fluorescência de raios X (Philips PW 2400). Os ensaios de DRX foram realizados em amostras em forma de pó em difratômetro Sheifert modelo URD 65, operando com radiação de $\mathrm{Cu}-\mathrm{k}_{\alpha}$ e $2 \mu$ variando de $5^{\circ}$ a $65^{\circ}$. A distribuição de tamanho de partícula foi determinada por peneiramento e sedimentação [10].

Foram elaboradas quatro composições com mistura de argila e chamote, conforme mostra a Tabela I. Estas composições foram homogeneizadas a seco em galga misturadora de pista lisa por $30 \mathrm{~min}$.

Corpos-de-prova retangulares foram conformados por extrusora de laboratório nas dimensões $100 \times 30 \times 11 \mathrm{~mm}^{3}$. Os corpos-de-prova foram inicialmente secos a temperatura ambiente por $72 \mathrm{~h}$ e, após, em estufa a $110{ }^{\circ} \mathrm{C}$ até massa constante. A queima dos corpos de prova foi realizada em forno industrial do tipo Hoffmann a $970{ }^{\circ} \mathrm{C}$. As propriedades tecnológicas determinadas foram: retração linear de secagem e queima, absorção de água e tensão de ruptura à flexão.

A análise microestrutural em amostras dos corpos de prova

Tabela I - Composições investigadas ( $\%$ em peso).

[Table I - Investigated compositions (wt. \%).]

\begin{tabular}{lcccc}
\hline Matérias-primas & \multicolumn{5}{c}{ Composição } \\
\hline & $\mathbf{0 C H}$ & $\mathbf{5 C H}$ & $\mathbf{1 0 C H}$ & $\mathbf{2 0 C H}$ \\
\hline Argila & 100 & 95 & 90 & 80 \\
\hline Chamote & 0 & 5 & 10 & 20 \\
\hline
\end{tabular}

queimados foi realizada por porosimetria de mercúrio e microscopia eletrônica de varredura. Os ensaios de porosimetria de mercúrio foram realizados num equipamento Quantachrome, Autoscan 33, para obtenção da distribuição de tamanho de poros entre $0,00648 \mu \mathrm{m}$ e 8,8884 $\mu \mathrm{m}$. Os ensaios de microscopia eletrônica de varredura foram realizados em microscópio Zeiss modelo DSM 962.

\section{RESULTADOS E DISCUSSÃO}

\section{Características do chamote}

A Tabela II apresenta algumas características do chamote. Observa-se que a composição química apresenta teores relativamente elevados de $\mathrm{Al}_{2} \mathrm{O}_{3}$ e baixos de óxidos alcalinos fundentes, $\mathrm{K}_{2} \mathrm{O}$ e $\mathrm{Na}_{2} \mathrm{O}$, típicos de argilas cauliníticas. $\mathrm{O}$ elevado teor de $\mathrm{Fe}_{2} \mathrm{O}_{3}$ confere a cor avermelhada dos blocos de vedação. Já o baixo teor de perda ao fogo PF está associada à a eliminação parcial de hidroxilas da gibsita $-\mathrm{Al}(\mathrm{OH})_{3}$ e da 
Tabela II - Características do chamote.

[Table II - Characteristics of the grog.]

\begin{tabular}{|c|c|c|c|c|c|c|c|c|c|}
\hline Composição Química (\% em peso) & & $\begin{array}{c}\mathrm{SiO}_{2} \\
55,98\end{array}$ & $\begin{array}{l}\mathrm{Al}_{2} \mathrm{O}_{3} \\
25,36\end{array}$ & $\begin{array}{c}\mathrm{Fe}_{2} \mathrm{O}_{3} \\
9,57\end{array}$ & $\begin{array}{l}\mathrm{TiO}_{2} \\
1,32\end{array}$ & $\begin{array}{l}\mathrm{K}_{2} \mathrm{O} \\
2,24\end{array}$ & $\begin{array}{c}\mathrm{Na}_{2} \mathrm{O} \\
0,64\end{array}$ & $\begin{array}{l}\mathrm{CaO} \\
0,37\end{array}$ & $\begin{array}{cc}\mathrm{MgO} & \mathrm{PF} \\
0,97 & 3,30\end{array}$ \\
\hline \multirow[t]{2}{*}{ Composição mineralógica } & \multicolumn{3}{|c|}{ Caulinita } & \multicolumn{3}{|c|}{ Mica muscovita } & \multicolumn{3}{|c|}{ quartzo } \\
\hline & \multicolumn{3}{|c|}{$\mathrm{X}$} & \multicolumn{3}{|c|}{$\mathrm{XX}$} & \multicolumn{3}{|c|}{ XXX } \\
\hline \multirow[t]{2}{*}{ Granulometria $\mu \mathrm{m}$ (\% em peso) } & $<2$ & & $2-6$ & \multicolumn{2}{|l|}{$6-20$} & $20-60$ & \multicolumn{2}{|c|}{$60-200$} & $200-600$ \\
\hline & 5 & & 10,6 & \multicolumn{2}{|l|}{15,7} & $\overline{17,8}$ & \multicolumn{2}{|c|}{35,1} & 15,8 \\
\hline
\end{tabular}

caulinita - $2 \mathrm{SiO}_{2} \cdot \mathrm{Al}_{2} \mathrm{O}_{3} \cdot 2 \mathrm{H}_{2} \mathrm{O}$, fases mineralógicas típicas das argilas locais. $\mathrm{O}$ chamote apresenta como fase cristalina predominante o quartzo, seguido de mica muscovita e caulinita. A presença de caulinita indica que a temperatura de queima não foi superior a $600{ }^{\circ} \mathrm{C}$, já que nesta temperatura a caulinita já perde sua cristalinidade devido à perda de água de constituição. Com relação à granulometria, o chamote apresenta um tamanho médio de partícula de $60 \mu \mathrm{m}$ e predominância de partículas com diâmetro variando de 60 a $200 \mu \mathrm{m}$.

Na Fig. 1 pode-se observar que o chamote é constituído principalmente por um agregado poroso de partículas. Observam-se ainda pequenas partículas de morfologia pseudohexagonal, associadas possivelmente ao argilomineral caulinita.

\section{Características e propriedades das composições}

A Fig. 2 mostra o diagrama de Winkler [11] com a localização das matérias-primas e composições estudadas. Este diagrama permite que o sistema cerâmico seja compreendido de acordo com três variações de tamanho de partícula, que são: (1) fração "argila", diâmetro $\phi<2 \mu \mathrm{m}$; (2) fração silte, $2 \mu \mathrm{m}<\phi<20 \mu \mathrm{m}$; (3) fração areia, $\phi>20 \mu \mathrm{m}$. Como o tamanho de partícula de uma argila pode se relacionar com o tipo de mineral, sua trabalhabilidade, que está relacionada com a plasticidade, pode ser indiretamente aferida. Observa-se que a argila pura, ou seja, composição $\mathbf{0 C H}$, está localizada na região 2 , apropriada para fabricação de telhas. Já o chamote, localiza-se na parte inferior do diagrama, apresentando predominância de partículas de tamanho $>20 \mu \mathrm{m}$, associadas ao quartzo. Nota-se na Fig. 2 que a incorporação de até $20 \%$ de chamote à argila, $20 \mathrm{CH}$, não altera a região de posicionamento. Isto é bastante apropriado e indica que a trabalhabilidade da massa é pouco afetada com a incorporação de chamote e ainda se mantém adequada para fabricação de telhas.

A Tabela III apresenta alguns parâmetros de pré-queima das composições. Pode-se observar que há uma redução do percentual de água de conformação com o incremento de chamote. Isto é devido à menor plasticidade do chamote em relação à argila. Pode-se observar também que a incorporação de chamote aumentou a densidade a úmido das composições. Este parâmetro é conseqüência da densidade de cada material, da quantidade destes materiais e do empacotamento das partículas. Como a densidade do chamote, $2,70 \mathrm{~g} / \mathrm{cm}^{3}$, é bem superior à da água, o menor teor de água das composições
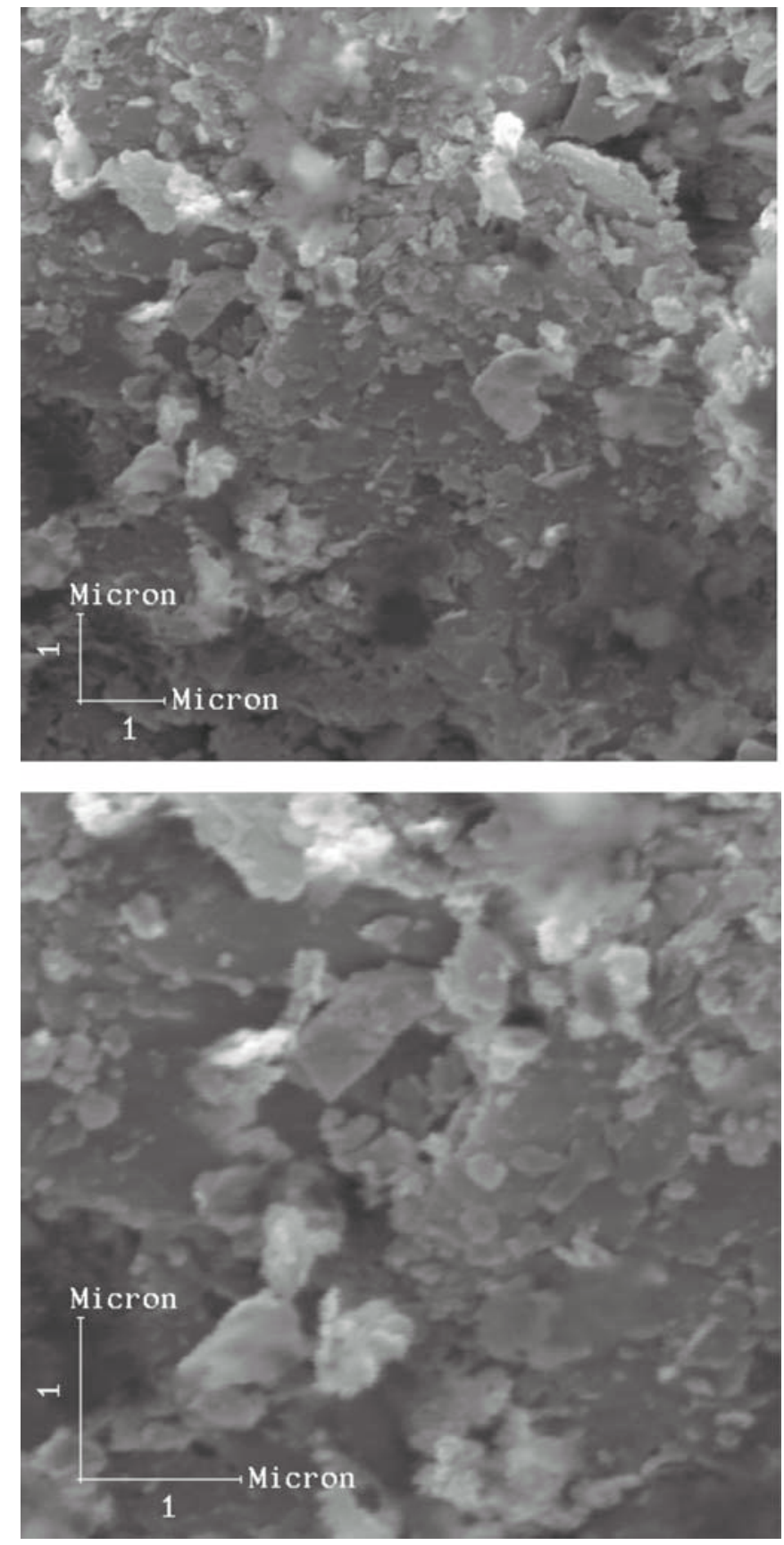

Figura 1: Micrografias obtidas por MEV das partículas de chamote. (a) $100 \mathrm{x}$; (b) $1900 \mathrm{x}$.

[Figure 1: SEM migrographs of the grog particules. (a) 1000x; (b) 1900 x.] 
com chamote contribui para melhorar a densidade a úmido das composições. A granulometria mais grosseira do chamote também pode ter contribuído para melhorar o grau de empacotamento das partículas. $\mathrm{O}$ incremento da densidade a úmido é, até certo ponto, benéfico já que pode contribuir para melhorar a resistência mecânica das peças úmidas. Entretanto, dependendo da morfologia das partículas, um aumento da densidade pode dificultar a secagem através do aumento da

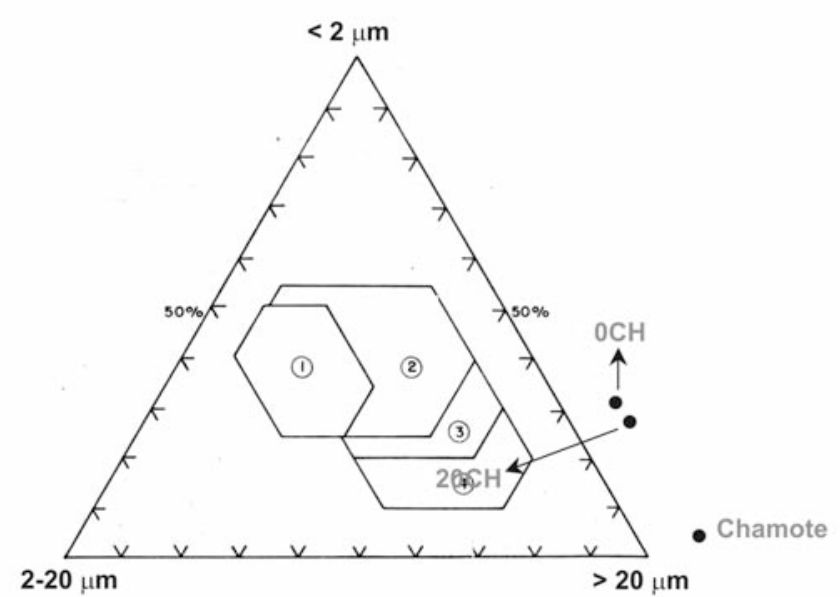

Figura 2: Diagrama de Winkler .

[Figure 2: Winkler diagram.]
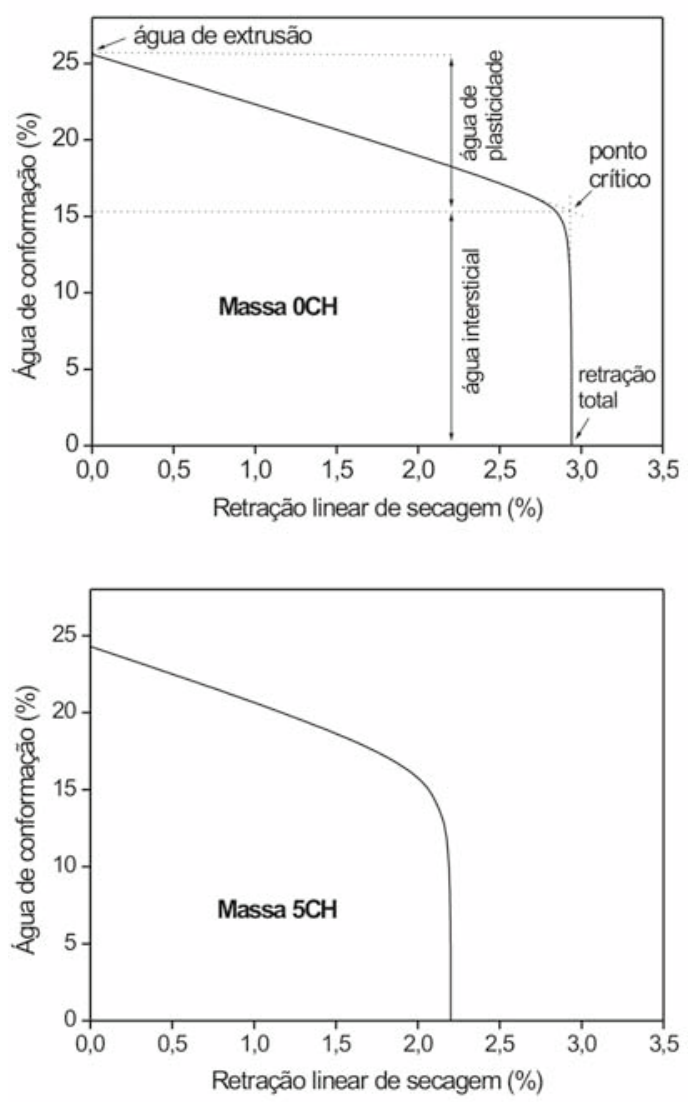

impermeabilidade das peças. Isto não acontece com o chamote devido à sua estrutura porosa. Observa-se também na Tabela III que a densidade a seco das composições é praticamente a mesma. Isto será discutido mais adiante, já que pode estar relacionado com o tipo de água existente na peça úmida. Por fim, observa-se que o incremento do percentual de chamote incorporado à argila reduziu a retração de secagem. Isto está relacionado com a redução na quantidade de água de conformação.

A Fig. 3 apresenta as curvas de Bigot das diversas composições investigadas. A curva de Bigot descreve a evolução da redução da água de conformação e aumento da retração de secagem das peças [12]. O conhecimento desta curva auxilia no entendimento da etapa de secagem, possibilitando, por exemplo, o estabelecimento de um ciclo de secagem.

A água de conformação pode ser dividida em dois tipos: o primeiro é denominado de água intersticial. O segundo é denominado de água livre ou água de plasticidade [1]. A água intersticial está relacionada com a água necessária para preencher os poros das partículas. Já a água de plasticidade localiza-se entre as partículas argilosas, separando-as e facilitando a trabalhabilidade no processo de conformação. É este último tipo de água que é responsável pela retração das peças. Em uma curva de Bigot é possível separar esses dois tipos de água a partir da localização do ponto crítico, como está ilustrado na curva para a composição sem chamote, $\mathbf{0 C H}$, na Fig. 3. A água de plasticidade, que é a primeira a sair, é
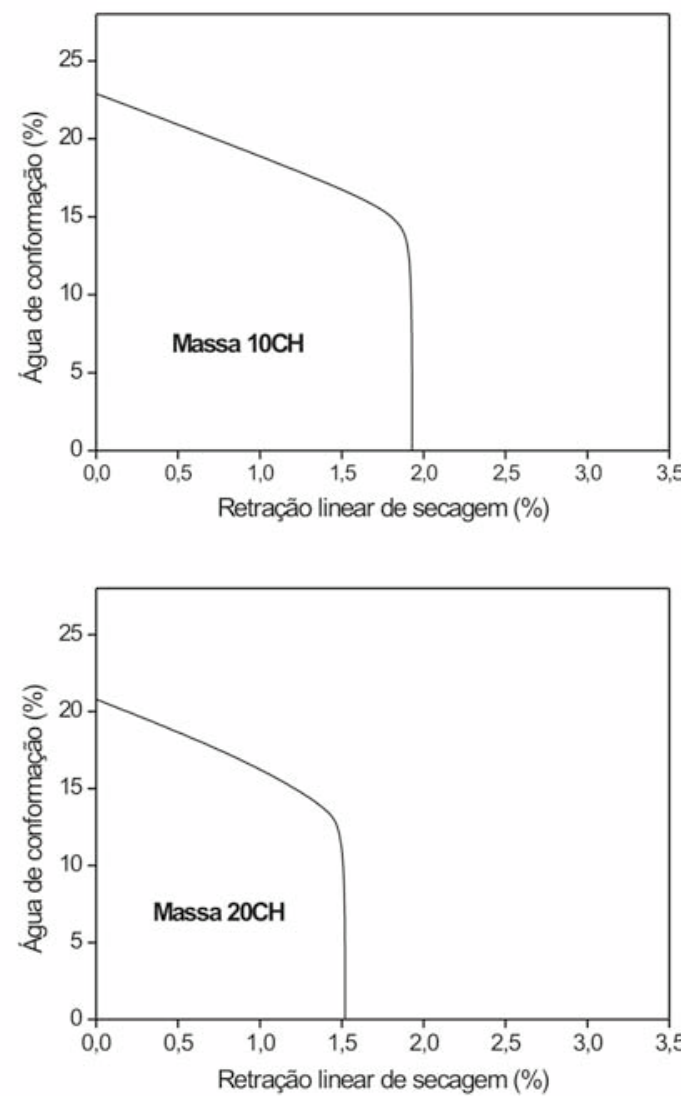

Figura 3: Curvas de Bigot para as composições investigadas.

[Figure 3: Bigot's curves for the investigated compositions.] 
Tabela III - Parâmetros de pré-queima das composições.

[Table III - Pre-firing parameters of the compositions.]

\begin{tabular}{llllll}
\hline Parâmetros & \multicolumn{5}{c}{ Composição } \\
\hline & $0 \mathrm{CH}$ & $5 \mathrm{CH}$ & $10 \mathrm{CH}$ & $15 \mathrm{CH}$ & $20 \mathrm{CH}$ \\
\hline Água de conformação $(\%)$ & 25,60 & 24,30 & 22,90 & 23,06 & 20,80 \\
\hline Densidade a úmido $\left(\mathrm{g} / \mathrm{cm}^{3}\right)$ & 1,92 & 1,94 & 1,97 & 1,98 & 2,00 \\
\hline Densidade a seco $\left(\mathrm{g} / \mathrm{cm}^{3}\right)$ & 1,73 & 1,72 & 1,74 & 1,72 & 1,73 \\
\hline Retração linear de secagem $(\%)$ & 3,59 & 2,50 & 1,96 & 1,80 & 1,52 \\
\hline
\end{tabular}

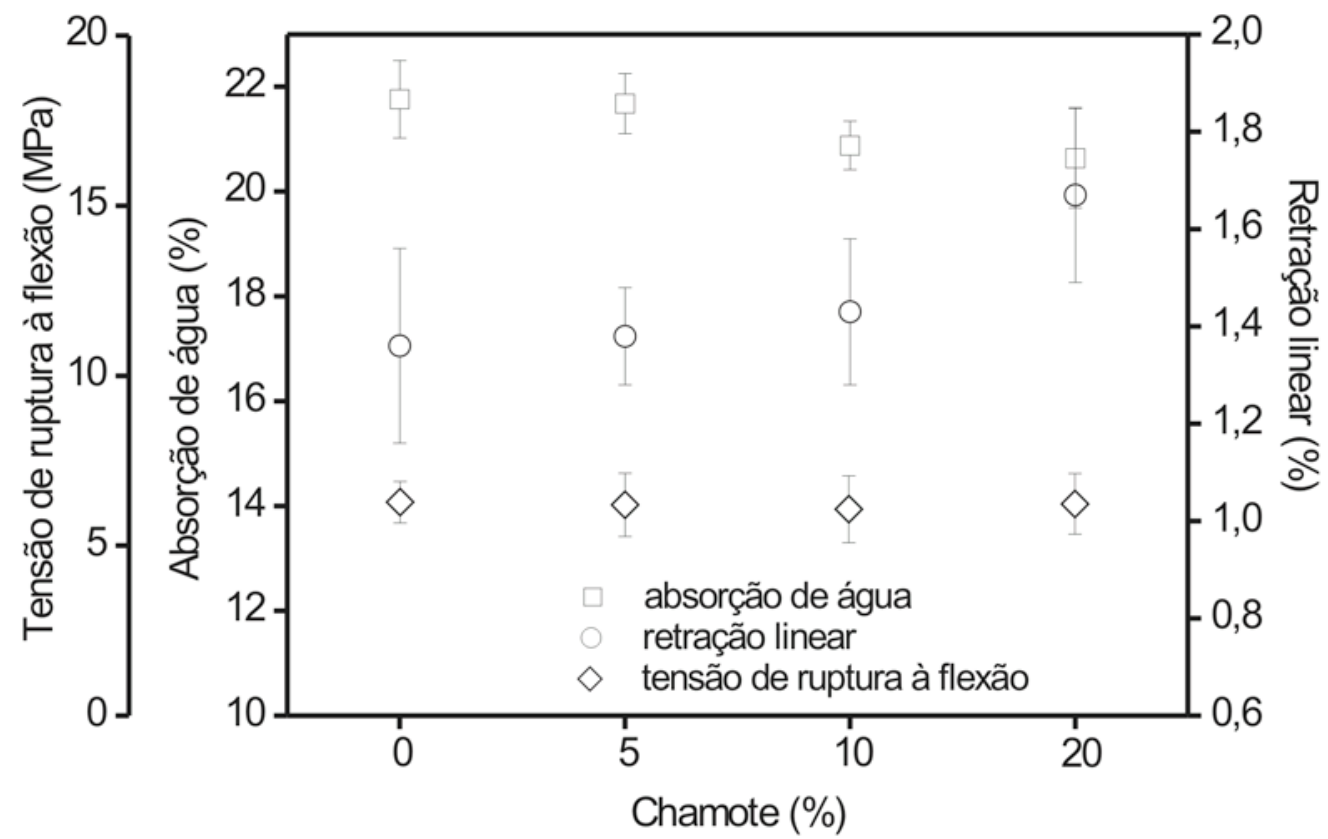

Figura 4: Propriedades de queima das composições em função do teor de chamote.

[Figure 4: Firing properties of the compositions as a function of the grog content.]

considerada crítica já que produz retração o que pode acarretar tensões e conseqüentemente levar ao aparecimento de trincas nas peças. Observa-se nos gráficos da Fig. 3 que a incorporação de chamote, reduz tanto a água intersticial, devido ao melhor empacotamento das partículas, quanto à água de plasticidade, devido ao menor teor de "fração argila".

A similaridade na densidade a seco das composições, apesar das diferenças obtidas na densidade das composições a úmido, indica que o grau de empacotamento a seco das partículas depende fundamentalmente da acomodação aleatória das partículas durante a saída de água de plasticidade.

A Fig. 4 apresenta, conjuntamente, a absorção de água, retração linear de queima e a tensão de ruptura à flexão das composições em função do teor de chamote incorporado.

Tabela IV - Parâmetros de porosidade das composições obtidos por ensaio de intrusão de mercúrio. [Table IV - Porosity parameters of the compositions obtained by mercury intrusion test.]

\begin{tabular}{lllll}
\hline Parâmetros & \multicolumn{4}{c}{ Composição } \\
\hline Volume de mercúrio intrudido $\left(\mathrm{cm}^{3} / \mathrm{g}\right)$ & $0 \mathrm{CH}$ & $5 \mathrm{CH}$ & $10 \mathrm{CH}$ & $20 \mathrm{CH}$ \\
\hline Porosidade aparente $(\%)$ & 0,1626 & 0,1770 & 0,1727 & 0,1657 \\
\hline Densidade aparente $\left(\mathrm{g} / \mathrm{cm}^{3}\right)$ & 30,40 & 32,18 & 31,65 & 30,76 \\
\hline Área superficial total $\left(\mathrm{m}^{2} / \mathrm{g}\right)$ & 1,87 & 1,82 & 1,83 & 1,86 \\
\hline Diâmetro médio de poro $(\mathrm{m}) \times 10^{-2}$ & 9,73 & 9,86 & 10,33 & 10,76 \\
\hline
\end{tabular}


Observa-se que, dentro do erro estatístico, a incorporação de chamote não alterou as propriedades de queima avaliadas. Com relação à retração linear, há uma tendência de aumento deste parâmetro com $20 \%$ de incorporação de chamote. Como o grau de empacotamento a seco das composições foi bastante similar e uma vez que a incorporação de chamote reduz a perda de massa durante a queima, pode-se associar esta tendência às reações de sinterização do chamote.

Em relação à absorção de água e à tensão de ruptura à flexão não são observadas alterações significativas com a incorporação de chamote. Como estas propriedades são fortemente dependentes da porosidade do material, os resultados obtidos podem ser um indicativo que as composições apresentam porosidade similar. Valores de absorção de água das composições na faixa de 21 a $22 \%$, estão de acordo com telhas industriais produzidas em Campo dos Goytacazes. Estes resultados mostram que a absorção de água encontra-se acima do limite máximo especificado por norma técnica, 18\%, [13].

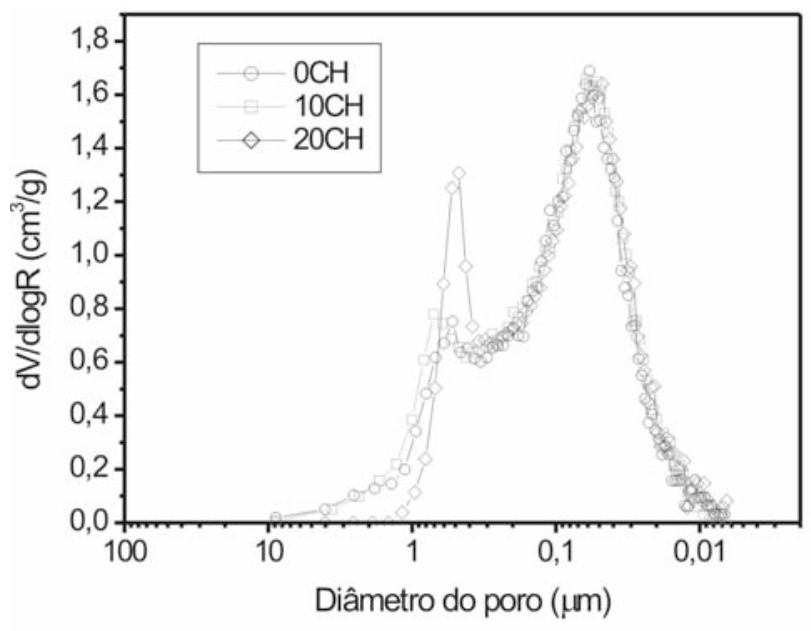

Figura 5: Curvas de distribuição de tamanho de poros das composições.

[Figure 5: Pore size distribution curves for the compositions.]
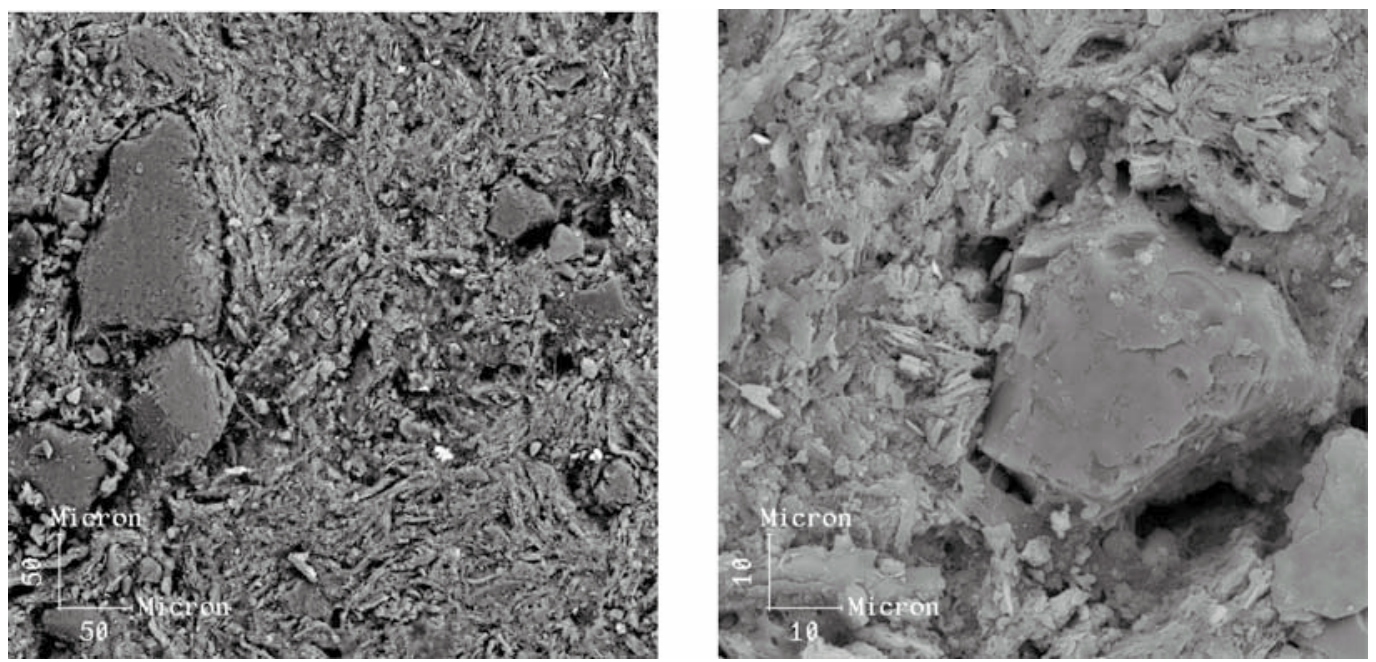

Figura 6: Micrografias obtidas por MEV da composição 0CH queimada a $970{ }^{\circ} \mathrm{C}$. (a) $200 x$. (b) $1000 x$. [Figure 6: SEM micrographs of the composition $0 \mathrm{CH}$ fired at $970{ }^{\circ} \mathrm{C}$. (a) $200 \mathrm{x}$. (b) $1000 \mathrm{x}$.]
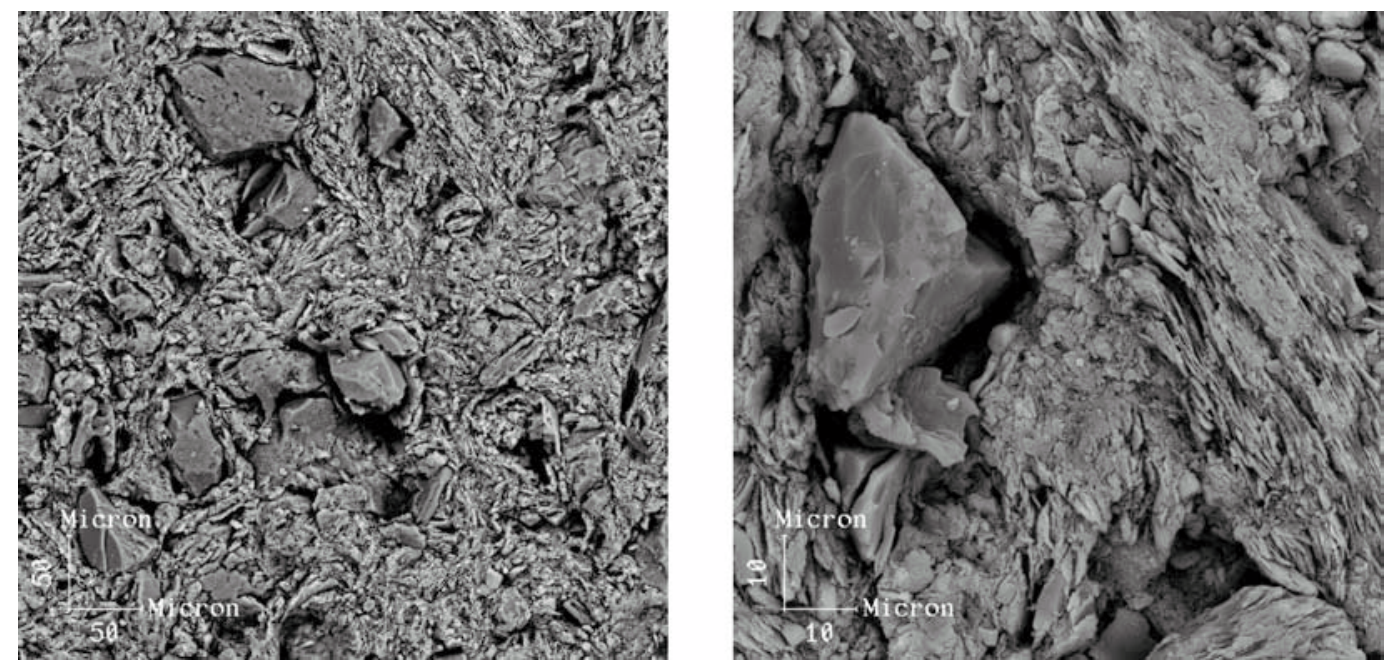

Figura 7: Micrografias obtidas por MEV da composição $20 \mathrm{CH}$ queimada a $970{ }^{\circ} \mathrm{C}$. (a) 200x. (b) 1000x. [Figure 7: SEM micrographs of the composition $20 \mathrm{CH}$ fired at $970{ }^{\circ} \mathrm{C}$. (a) $200 \mathrm{x}$. (b) $1000 \mathrm{x}$. ] 
Isto é atribuído fundamentalmente à predominância caulinítica das argilas de Campos dos Goytacazes, que apresentam um comportamento refratário durante a queima.

\section{Microestrutura das composições}

A Tabela IV apresenta dados obtidos a partir do ensaio de porosimetria de mercúrio. O maior volume de mercúrio intrudido com a incorporação de chamote, associa-se à maior porosidade aparente, menor densidade aparente e maior área superficial específica total em comparação com a argila pura. Observa-se também que a composição $\mathbf{2 0 C H}$ apresenta um diâmetro médio de poros menor que o da massa argilosa $\mathbf{0 C H}$. Isto é conseqüência de uma distribuição de tamanho de poros mais estreita com menor percentual de poros de maior tamanho.

A Fig. 5 apresenta as curvas de distribuição de tamanho de poros das composições queimadas a $970{ }^{\circ} \mathrm{C}$. Pode-se observar que as composições apresentam uma predominância de poros com tamanhos compreeendidos entre $0,048 \mu \mathrm{m}$ e $0,067 \mu \mathrm{m}$ correspondentes aos limites dos três picos de maior incidência de poros das composições $\mathbf{0 C H}, \mathbf{1 0 C H}$ e 20CH. Pode-se observar também que a composição com $20 \%$ de chamote apresenta uma distribuição de poros mais estreita e com poros de menor tamanho quando comparada com argila pura, $\mathbf{0 C H}$, e argila com $10 \%$ de chamote, $\mathbf{1 0 C H}$. Como o empacotamento a seco das composições foi similar, o menor tamanho máximo de poros obtido para a composição $20 \mathrm{CH}$ pode ser atribuído às características dos poros das peças secas. Talvez a menor perda de massa durante a queima da composição $20 \mathrm{CH}$ em relação às demais possa também contribuir para este comportamento.

De uma maneira geral, pode-se concluir que a incorporação de chamote na massa argilosa acarretou uma alteração praticamente insignificante na porosidade aberta das peças queimadas. Os valores similares dos parâmetros obtidos para a composição com $20 \%$ de chamote, $2 \mathbf{0 C H}$, e massa argilosa, $\mathbf{0 C H}$, indicam que a partir de $20 \%$ de chamote talvez possa haver até uma redução de porosidade.

As Figs. 6 e 7 mostram as micrografias obtidas por MEV da argila pura, $\mathbf{0 C H}$, e da composição com incorporação de $20 \%$ de chamote, $\mathbf{2 0} \mathbf{C H}$, respectivamente. Observa-se que ambas as composições apresentam uma textura rugosa e significativa porosidade. Esta porosidade pode ser proveniente de diversas causas. Estas causas seriam: vazios oriundos do empacotamento das partículas, eliminação de gases e vapor d'água durante a queima, bem como fissuras entre uma matriz possivelmente amorfa de alumino-silicato e partículas de quartzo de variados tamanhos. Este último tipo de porosidade é bem conhecido na literatura [14-16], sendo atribuída à transformação alotrópica do quartzo que ocorre em temperaturas em torno de $573{ }^{\circ} \mathrm{C}$ com redução de volume.

As características observadas para as composições estudadas, Figs. 6 e 7, são influenciadas pela temperatura de queima utilizada. As cerâmicas argilosas queimadas em temperaturas em torno de $970{ }^{\circ} \mathrm{C}$, típica de cerâmica vermelha, não apresentam ainda uma consolidação microestrutural eficiente. Por isso, é comum a ocorrência de elevada porosidade e textura rugosa.

\section{CONCLUSÕES}

Neste presente trabalho, foi observado que a incorporação de chamote em até $20 \%$ em peso possibilita uma melhoria nos parâmetros pré-queima. Após queima, a pouca variação na porosidade resulta da transformação que o chamote sofre durante a queima sob temperaturas acima da que foi obtido. Assim, a característica peculiar das indústrias cerâmicas de Campos dos Goytacazes de apresentarem uma elevada produção de blocos de vedação queimados em baixa temperatura, pode possibilitar o aproveitamento dos rejeitos de queima, ou seja, dos chamotes, para melhorar o processamento das telhas cerâmicas, sem comprometer a qualidade do produto final

\section{AGRADECIMENTOS}

Os autores agradecem ao CNPq pelo auxílio para realização deste trabalho, Proc. 150444/2003-6, INT/LATEP pela realização de ensaios de porosimetria de mercúrio e UFRJ/ COPPE pelos ensaios de microscopia eletrônica de varredura.

\section{REFERÊNCIAS}

[1] V. Beltran, E. Ferrando, J. García, E. Sánchez, Tile \& Brick Int. 11, 3 (1995) 169.

[2] V. Beltran, E. Sánchez, J. García, E. Ferrando, Tile \& Brick Int. 12, 4 (1996) 320.

[3] S. Pracidelli, F. G. Melchiades, Cerâmica Industrial 2, 1-2 (1997) 31 .

[4] F. Ripoli Filho, Cerâmica 43, 281-282 (1997) 133.

[5] J. Vicenzi, D. L. Villanova, T. P. Madruga, C. P. Bergmann, Anais do $55^{\circ}$ Congresso Anual da ABM, Rio de Janeiro, RJ (2000) cdrom, 1579.

[6] D. L. Villanova, J. Vicenzi, T. P. Madruga, C. P. Bergmann, Anais do $55^{\circ}$ Congresso Anual da ABM, Rio de Janeiro, RJ (2000) cdrom, 1569.

[7] Manfredini \& Schianchi do Brasil Ltda, Cerâmica Industrial 7, 6 (2002) 34.

[8] C. M. F. Vieira, S. N. Monteiro, J. Duailibi Filho, Cerâmica Industrial 6, 6 (2001) 43.

[9] S. N. Monteiro, C. M. F. Vieira, Tile \& Brick Int. 18, 3 (2002) 152.

[10] ABNT - Associação Brasileira de Normas Técnicas, Determinação da Análise Granulométrica de Solos, NBR 7181, Rio de Janeiro (1984).

[11] H. Heystek, Desired properties of clay minerals in ceramics, American Ceramic Society Convention, Chicago (1964).

[12] S. Oller, Cerâmica 27, 140 (1981) 319.

[13] ABNT - Associação Brasileira de Normas Técnicas, Telha Cerâmica Tipo Romana: Especificação, NBR 13.582, Rio de Janeiro (1996).

[14] S. I. Warshaw, R. Seider, J. Am. Ceram. Soc. 50 (1967) 337.

[15] V. Kilikoglou, G. Vekinis, Y. Maniatis, Acta Metall. Mater. 43, 8 (1995) 2959.

[16] S. Maity, B. K. Sarkar, J. Eur. Ceram. Soc. 16 (1996) 1083. (Rec. 28/04/04, Ac. 07/05/04) 